\title{
Behavior of dolphinfish (Coryphaena hippurus) around drifting FADs as observed from automated acoustic receivers
}

\author{
Marc Taquet ${ }^{1}$, Laurent Dagorn ${ }^{2}$, Jean-Claude Gaertner ${ }^{3}$, Charlotte Girard ${ }^{2}$, Riaz Aumerruddy ${ }^{4}$, \\ Gorka Sancho ${ }^{5}$ and David Itano ${ }^{6}$ \\ IFREMER, CRH - HMT, Av. J. Monnet, BP 171, 34203 Sète Cedex, France \\ 2 Institut de Recherche pour le Développement, CRH, Av. Jean Monnet, BP 171, 34203 Sète Cedex, France \\ ${ }^{3}$ Centre d'Océanologie de Marseille, LMGEM, UMR CNRS 6117, rue de la Batterie des Lions, 13007 Marseille, France \\ 4 Seychelles Fishing Authority, PO Box 449, Victoria, Mahé, Seychelles \\ 5 College of Charleston, Grice Marine Laboratory, 205 Fort Johnson Rd., Charleston, SC 29412, USA \\ ${ }^{6}$ University of Hawaii, JIMAR, Pelagic Fisheries Research Program, 1000 Pope Rd. MSB 312, Honolulu, HI 96822, USA
}

Received 2 November 2007; Accepted 17 December 2007

\begin{abstract}
To study the behavior of dolphinfish (Coryphaena hippurus) around drifting Fish Aggregating Devices (FADs), we tagged individuals with long-lived, coded sonic transmitters and attached automated sonic receivers to drifting FADs in two regions of the Western Indian Ocean. Among the three tagging methods used in this study (surgery, external hooks, underwater bait without capture), the latest resulted in residence times significantly shorter than the other ones, likely due to regurgitation. Dolphinfish tagged with the two other methods usually stayed several days associated to FADs (Kaplan-Meier survival analysis 5.09 days, mean 6.25 days, SD 4.39 days, maximum 15.26 days), drifting with them. There was no significant difference in the residence times of dolphinfish in equatorial and tropical areas. While associated to FADs, dolphinfish spent most of their time close to floating object $(<365 \mathrm{~m})$. The total time spent away from FADs was low (median 8\%), and likely corresponded to making feeding excursions. Dolphinfish did not form a single school while associated to a given FADs, but formed multiple small schools. FADs are likely to be sites with exchanges of individuals between schools. These results are discussed in regards to the possibility of FADs acting as ecological traps and the validity of meeting-point hypotheses as an explanation for fish aggregations under floating objects.
\end{abstract}

Key words: Dolphinfish / FAD / Acoustic tagging / Ultrasonic telemetry / Behavior of fish / Ecological trap / Meeting point / Indian Ocean

Résumé - Comportement des dorades coryphènes (Coryphaena hippurus) autour des DCP dérivants, observé à l'aide de marques acoustiques et de stations d'écoute. Afin d'étudier le comportement agrégatif de la dorade coryphène (Coryphaena hippurus) autour de dispositifs de concentration de poissons (DCP) dérivants, nous avons marqué plusieurs individus à l'aide d'émetteurs acoustiques et équipé les DCP dérivants autour desquels ils étaient agrégés, de stations de réception acoustique. Ces opérations de marquage ont été réalisées dans deux différentes régions de l'Ouest de l'océan Indien. Parmi les 3 méthodes de marquages utilisées au cours de cette étude (chirurgie, fixation externe par un hameçon, appât sous-marin sans capture), la dernière citée conduit à des temps de résidence significativement plus courts que les deux autres, sans doute à cause d'un phénomène de régurgitation de la marque. Les dorades coryphènes marquées à l'aide des deux autres méthodes restent généralement plusieurs jours associées aux DCP dérivants. La courbe de survie de Kaplan-Meier donne un temps de résidence de 5,09 jours pour $50 \%$ des poissons agrégés et une durée moyenne de résidence de 6,25 \pm 4,39 jours (durée maximale : 15,26 jours). Les temps de résidence enregistrés dans les différentes zones (équatoriale et tropicale) ne sont pas significativement différents. Lorsqu'elles sont associées aux DCP, les dorades coryphènes passent la majorité de leur temps près de l'objet flottant $(<365 \mathrm{~m})$. La proportion du temps passé loin du DCP est faible (médiane $8 \%$ ) et semble correspondre à des excursions à des fins alimentaires. Les dorades coryphènes ne forment pas un seul banc unique lorsqu'elles sont agrégées à un DCP donné, mais plutôt de multiples petits groupes. Il semble que les DCP soient des sites d'échange où les dorades coryphènes peuvent passer d'un groupe à l'autre. Ces résultats sont discutés en référence à la théorie du «piège écologique » et à l'hypothèse du «point de rencontre » qui est généralement formulée comme une des explications possibles de l'agrégation des poissons sous les objets flottants. 


\section{Introduction}

Some tropical pelagic fishes naturally aggregate around floating objects, which can be natural (logs, etc.) or man-made, usually called Fish Aggregating Devices (FADs). Most of behavioral studies related to pelagic fishes and FADs have been done on tropical tuna and on anchored FADs (see Dempster and Taquet 2004). Active sonic tracking studies have revealed that yellowfin tuna (Thunnus albacares) perform movements between FADs (Holland et al. 1990; Marsac and Cayré 1998; Brill et al. 1999; Dagorn et al. 2000). A detailed path analysis of these tracking data demonstrated that yellowfin tuna can orient themselves towards a FAD from about $10 \mathrm{~km}$ (Girard et al. 2004). Ohta and Kakuma (2005) and Dagorn et al. (2007), tagging tuna with long-lived coded acoustic transmitters and equipping anchored FADs with automated sonic receivers (listening stations), determined that the average stay of bigeye and yellowfin tuna around anchored FADs is about 5-8 days, though displaying a high variability (from a few minutes up to several weeks). Fish at FADs have also been observed performing excursions away from FADs, and are commonly considered result foraging activities away from the FADs (Holland et al. 1990; Ohta and Kakuma 2005).These behavioral studies are necessary pre-requisites to determining the effects of FADs on fish behavior, which is presently an urgent issue for pelagic fisheries management (Fonteneau 2003).

While dolphinfish (Coryphaena hippurus) is a major target species of anchored FAD artisanal fisheries (Taquet 2004) and a major by-catch species of purse seiners exploiting drifting FADs (Romanov 2002), it is surprising to notice that very few behavioral data are available on this species (Dempster and Kingsford 2003; Kingsford 2003). Girard et al. (2007) determined that displaced dolphinfish could home back to FADs from at least $820 \mathrm{~m}$, but there is no basic information on their residence times at FADs, which is essential to determine the effects of FADs on this species.

The use of acoustic tags and acoustic receivers is a popular, efficient and simple technique to study site fidelity (e.g. Heupel et al. 2004; Ohta and Kakuma 2005; Topping et al. 2006; Dagorn et al. 2007) and schooling behavior of large pelagic fishes (e.g. Klimley and Holloway 1999).

The overall objective of this study is to improve our knowledge on the behavior of dolphinfish around FADs. In this study we equipped dolphinfish with long-lived, individually coded acoustic transmitters and equipped drifting FADs in two distinct regions of the Western Indian Ocean (equatorial and tropical zones) with automated acoustic receivers. Specifically we intended to address the following questions:

- How long do dolphinfish stay around drifting FADs?

- Does residence time vary between geographical regions?

- Do dolphinfish perform such excursions? Does this behavior represent a major part of their activity while at FADs?

- Do all dolphinfish around a FAD form a single school, or are they distributed in several schools around the FAD?

- Do different tagging methods have an influence on residence time of dolphinfish?

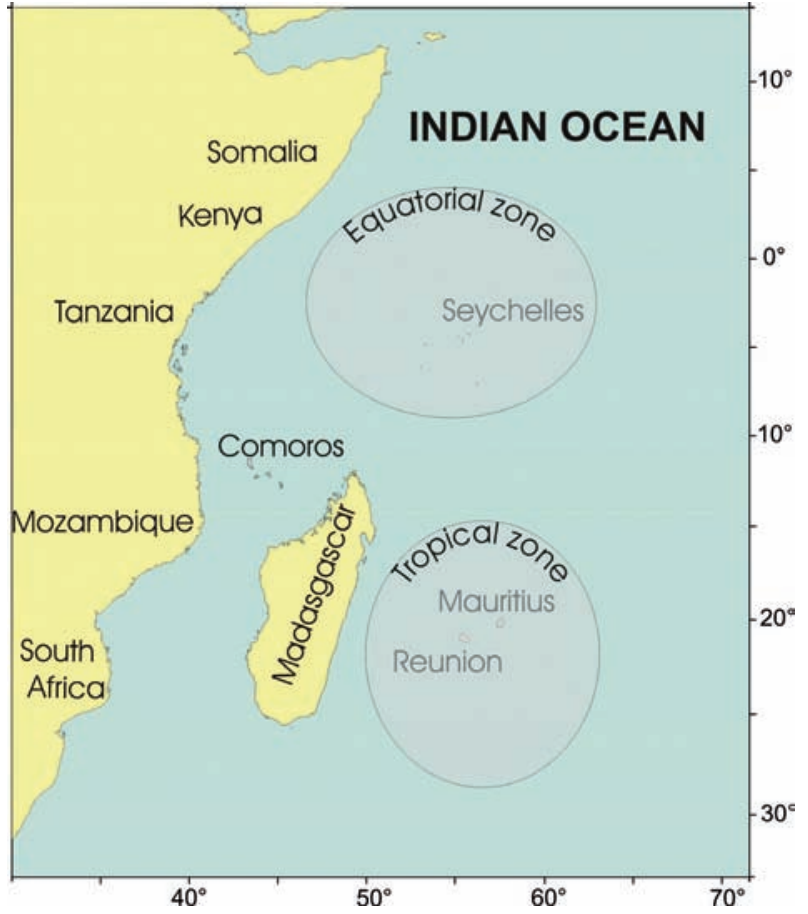

Fig. 1. Map of the two studied areas in the Indian Ocean.

\section{Material and methods}

\subsection{Study areas and acoustic receivers}

Tagging was performed around 10 drifting FADs in two regions of the Indian Ocean: 5 FADs in a tropical area southwest of Reunion Island and 5 FADs in an equatorial area off the Seychelles Islands (Fig. 1). In the southwest of Reunion Island, we worked around experimental drifting FADs that were all deployed by the scientific team. In the equatorial zone, we tracked fish around commercial FADs deployed by tuna purse seiners. All FADs consisted of floating bamboo rafts with trailing netting panels or large rice bags. These trailing materials in principle prevented the winds from directly affecting the drifting trajectory of the FADs, which therefore drifted in the surface water layer according to the local surface currents. Acoustic receivers (Vemco VR2, or VR3-Argos) were attached to the drifting FADs so the hydrophones were located about $5 \mathrm{~m}$ under the surface.

\subsection{Tagging and data collection}

We used two types of $69 \mathrm{kHz}$ acoustic tags: Vemco V8 tags (V8SC-2H-R256, 40-120 s delay, V8-2H-R256, 30-90 sec. delay, V8SC-2L-R256, 5-15 s), and Vemco V16P tags (V164H-S256, 10-35 s delay). Three different types of tagging techniques were used. The first two techniques required the capture of dolphinfish by trolling artificial lures. Captured fish were put on their backs on a padded cradle, their eyes were covered with a wet smooth piece of cloth (chamois) and a hose inserted in its mouth ensured a continuous flow of salt water through the gills. We first inserted tags in the peritoneal cavity 
(method 1) using standard surgical tag implantation techniques (see Meyer and Holland 2000; Schaefer and Fuller 2002). A scalpel was used to make a 1-2 cm long incision in the muscle of the abdominal wall about $2 \mathrm{~cm}$ anterior to the anus and $2-3 \mathrm{~cm}$ to one side of the ventral midline. To avoid possible damage of organs by the scalpel, final entry into the abdominal cavity was made using a latex gloved finger to rupture the peritoneal lining. The second tagging technique (method 2) was external, consisting in externally attaching tags with a barbed hook inserted through the anal fin base of the fish (Taquet 2004). The third technique (method 3) did not involve catching the dolphinfish, but tags were inserted into a whole small pelagic fish (Selar crumenophthalmus) used as bait. Divers swimming around the FAD would suspend the bait employing monofilament fishing line, which ended in a very thin section meant to easily break away. When dolphinfish ingested the bait with the tag, it would be temporarily retained in the stomach. With this method divers visually estimated the length of the tagged dolphinfish.

The acoustic range of the tags is dependent on their power output (V8 being less powerful than V16), but is also strongly influenced by the environmental conditions (Pincock and Voegeli 1990). For this reason, we performed range tests using a FAD anchored at 12 nautical miles off Reunion Island. Tests were performed on a day with sea conditions (force 3 winds) and moderate current ( 0.2 knots $)$ which are characteristic of both study areas. Two VR2 listening stations were attached under the FAD at two different depths (5 and $20 \mathrm{~m}$ ) and two tags (V8 and V16P) were placed in individual small net bags suspended ( 6 and $50 \mathrm{~m}$ of depth) from a research vessel that drifted with the engines off to a distance of $1.8 \mathrm{~km}$ off the FAD. The position of the anchored FAD was registered using a GPS at the beginning and at the end of each drifting operation, while the positions of the vessel were registered every $30 \mathrm{~s}$ during the range testing. After repeating the tests five times, the last detections obtained with V8 and V16P tags were at $365 \mathrm{~m} \pm 35 \mathrm{~m}$ and $655 \mathrm{~m} \pm 60 \mathrm{~m}$, respectively.

VR2 listening stations attached to drifting FADs needed to be recovered to download stored tag detection data. Therefore, the monitoring around FADs equipped with VR2 receivers was stopped at the end of the scientific cruises. In some cases, dolphinfish were still associated with the FAD and their residence times were underestimated. Thanks to their satellite links, the new VR3 receivers transmitted data for months after deployment and it was not necessary to recover them to download the stored data (Dagorn et al. 2007b). Unfortunately, due to limitations in the satellite transmission time, the VR3 receiver could not send all the data recorded from individual tagged fish, but only transmitted summaries of the recorded detections. Therefore data downloaded from VR3 receivers through satellite links did not have enough precision to measure short excursions of tagged individuals away from the FADs (see Dagorn et al. 2007b for more details on the specification of this new VR3 receiver).

\subsection{Data analyses}

For each tagged fish we estimated continuous residence times (CRT) around a given FAD, defined as the time from

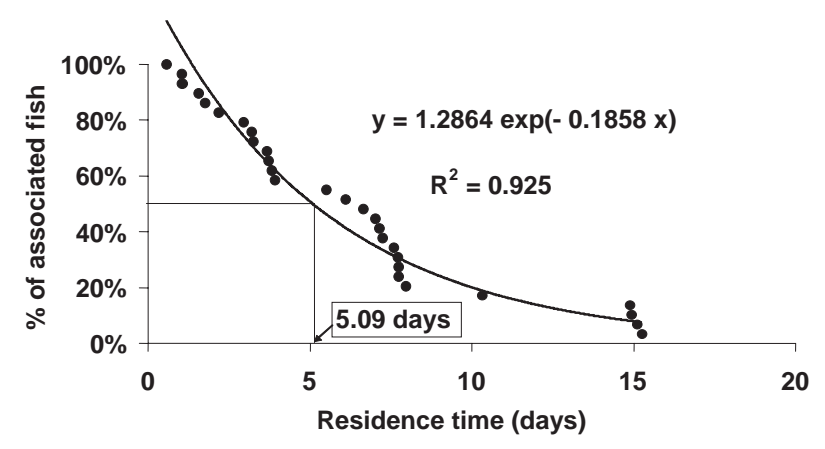

Fig. 2. Survival analysis of Kaplan-Meier defining the residence time of dolphinfish around FADs.

the first to the last detection without a day-scale absence (Ohta and Kakuma 2005). To determine the median residence time of dolphinfish around FADs from CRT estimates, we employed a Kaplan-Meier survival analysis model (Ohta and Kakuma 2005), fitting a curve in order to estimate the residence times at $50 \%$ (Fig. 2).

We hypothesized that residence times of dolphinfish around FADs could depend (i) on the tagging method, and (ii) on the area where fish were tagged. We first compared the CRT of dolphinfish tagged with different methods within each area. Tagging methods 2 and 3 were compared using a Wilcoxon rank-sum test in the tropical area (method 1 was only used on one fish in this area), and methods 1 and 2 were compared in the equatorial area (method 3 not used in this area). If tagging methods resulted in similar residence times within a region, the CRT data were aggregated in order to study regional differences in residence times.

We interpreted that fish were making excursions when they were not detected by an acoustic receiver for more than $30 \mathrm{~min}$ (detection radiuses of 365 or $655 \mathrm{~m}$, depending on the type of tag). The time to detect all the tags present around a receiver depends on the time intervals at which tags emit signals, which determines the likelihood of collisions occurring between signals of different tags (estimates were made with free software available at http://www.vemco.com). Signal collisions result in neither tag signal being detected by the receiver. For that reason, detections of fish tagged around FAD No. 789 (Table 1) were not used in this analysis as many fishes (17) were tagged with tags with short transmission intervals (5-15 s), which greatly increases signal collision rate. FAD observations employing VR2 receivers (except FADs equipped with VR3 as this receiver does not allow measuring such precision) were retained, for analyses since the minimum times to detect all tags around the FAD were estimated to be less than $30 \mathrm{~min}$. A residence time period (RT) therefore corresponds to a continuous presence of a fish around a FAD without an absence superior to $30 \mathrm{~min}$. Finally, details of fish association-excursion periods were analysed for 28 fish. The fish tagged around FAD No. 789 and those tagged around FADs equipped with VR3 were removed of the data set for this particular analysis. The periodicity of the excursions was also analysed regarding their distribution within the 24 hours of the day-night cycle.

To investigate the schooling behavior of dolphinfish at FADs, synchronous departures of multiple individuals were 
Table 1. Characteristics of the tagging experiments on the dolphinfish around drifting FADs in the Indian Ocean. Tag types: V8SC or V16SC. Listening station types are VR2, except some FADs equipped with a VR3 listening station (in bold). Continuous residence time (CRT in days); Zone: T (tropical area, La Reunion Islands); E (equatorial area, Seychelles).

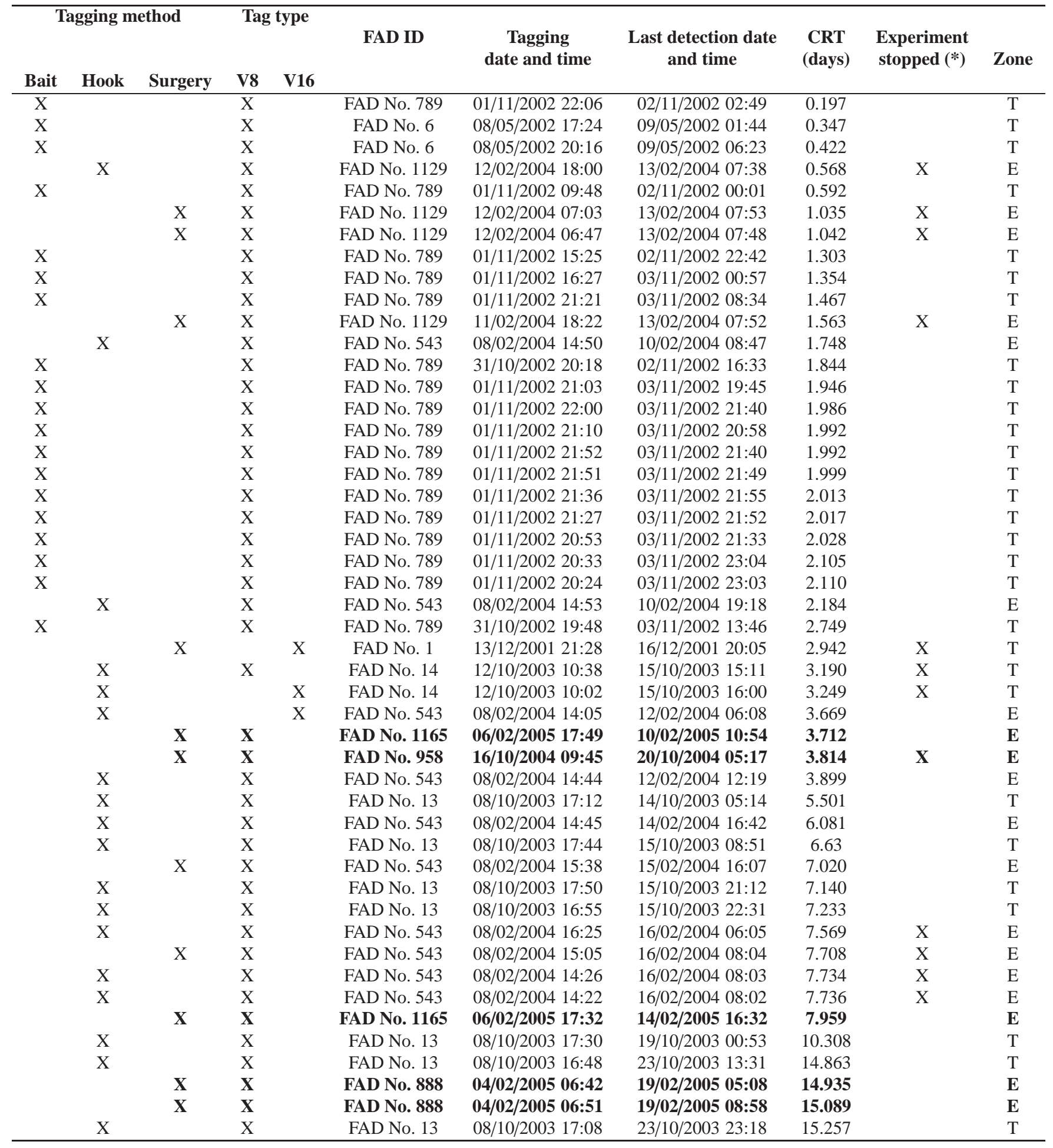

(*) In this cas, the natural departure of the dolphinfish from the FADs could not be observed (end of the scientific cruise or fishing operation on the surveyed FAD). 
calculated by measuring the time lags between definitive departures from a same FAD. We only retained for this analysis the three FADs where we tagged the most dolphinfish (FADs No. 543, No. 13 and No. 789). We considered as synchronous departures the events that occurred within a one hour period, and measured the proportion of fish tagged in the aggregation leaving the FAD together (see Dagorn et al. 2007a). We also investigated the schooling behavior of dolphinfish by examining the details of association and excursions of fish around one FAD (No. 13).

\section{Results}

A total of 60 dolphinfish ranging from 80 to $125 \mathrm{~cm}$ in fork length were tagged: 35 southwest of Reunion Island (tropical waters) and 25 off the Seychelles (equatorial waters) (Table 1).

\subsection{Residence times of dolphinfish around drifting FADs}

No detections were recorded by acoustic receivers from four dolphinfish (6.7\% of all tagged fish). Eight fishes showing residence times less than one hour were considered to have been injured or negatively stressed by the fishing or tagging operations, and were removed from further analyses. Therefore, the following analyses were only performed on the remaining 48 tagged individuals.

Residence times of dolphinfish in the tropical area tagged with method 3 appear to be significantly shorter than residence times of individuals tagged with method $2(Z=-4.182, p=$ $0)$. Residence times of fish tagged with methods 1 (surgery) and 2 (hook attachment) in the equatorial area are not different. Because we considered that method 3 (voluntary feeding) could have resulted in "artificial" shorter residence times (see discussion), we removed them to compare residence times in each area. Average residence times in the tropical area (mean $=7.63$ days; $n=10$ ) were not statistically different (Wilcoxon rank-sum test) from equatorial waters (mean = 5.53 days; $n=19$ ). Therefore, we combined all residence times of dolphinfish tagged with methods 1 and 2 in the two areas to calculate the mean CRT of dolphinfish around drifting FADs in the Western Indian Ocean (6.25 days; SD $=4.39)$, and the median of the survival analysis (5.09 days). Four fish stayed associated to FADs about two weeks, with the longest track being 15.26 days (Table 1), while drifting for more than $330 \mathrm{~km}$, from the southwest of Reunion Island to far in the south of Madagascar.

The mean duration of excursions away from FADs (Fig. 3) were quite constant $(1 \mathrm{~h} 37, \mathrm{SD}=1 \mathrm{~h} 10)$. No fish exhibited any excursions longer than 24 hours away from the associated FADs. However, some fish stayed associated to FADs more than three days without a single 30 -min absence period. Dolphinfish were detected at FADs $92 \%$ (median value) of the time (Fig. 4). In order to illustrate the association-excursion patterns observed we show the dynamics of the seven fish tagged on FAD No. 13 (Fig. 5). This example is representative of what we observed on all other FADs. There is no real pattern, and specific frequency of excursions was different from

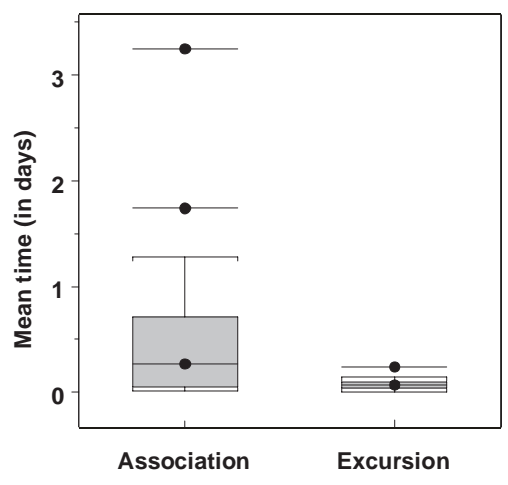

Fig. 3. Mean duration time of the association and excursion periods for dolphinfish aggregated around drifting FADs. The boxes represent the quartiles around the median (line inside the box); the dots outside the box stand for outliers.

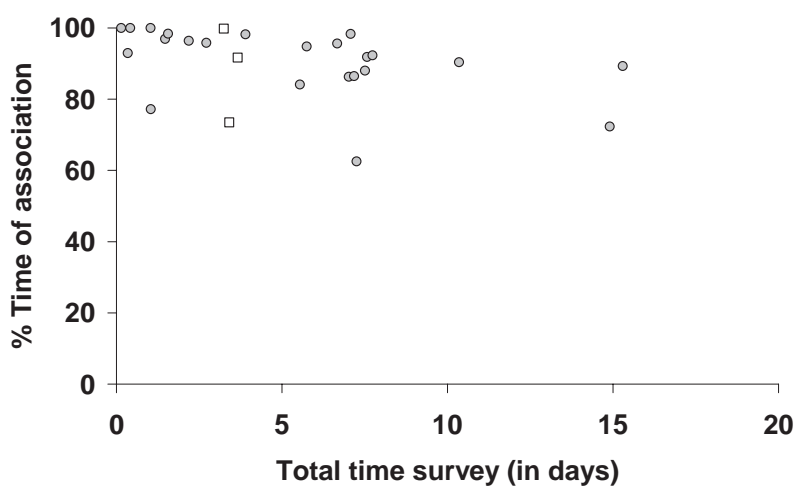

Fig. 4. Proportion of the associated time versus total observation time for dolphinfish aggregated around drifting FADs. (o) V8 tag, ( $\square$ ) V16P tag.

Table 2. Proportion of synchronous departures for tagged dolphinfish from the FADs within different time lags.

\begin{tabular}{llcccc}
\hline FAD & Nb Fish & $1 \mathrm{~h}$ & $6 \mathrm{~h}$ & $12 \mathrm{~h}$ & $24 \mathrm{~h}$ \\
\hline FAD No. 789 & 17 & $53 \%$ & $94 \%$ & $100 \%$ & $100 \%$ \\
FAD No. 13 & 7 & $0 \%$ & $28 \%$ & $57 \%$ & $71 \%$ \\
FAD No. 543 & 6 & $0 \%$ & $0 \%$ & $67 \%$ & $100 \%$ \\
\hline
\end{tabular}

one fish to the other. Regarding the periodicity of the excursions, the comparison of day-night activities for the 28 fish analyzed showed that $60 \%$ of excursions occurred during the day and $40 \%$ during the night (Fig. 6). Except for a progressive increase in the number of excursions around sunrise, no clear excursion pattern was observed within the 24 hour cycle.

We analyzed synchronous departures of groups of fish from three FADs to study schooling behavior of dolphinfish (Fig. 7). For each FAD, the departure of the first tagged dolphinfish was used as a starting point to calculate time lags (in hours) between the departures of other fish. The proportions of synchronous departures were calculated with reference to four different time lags (Table 2). Synchronous departures (i.e. with time lags less than one hour) were observed at one FAD (No. 789) where eight fishes left the FAD at the same time. In other FADs the time lags between two consecutive departures often lagged over six hours. These results were confirmed 


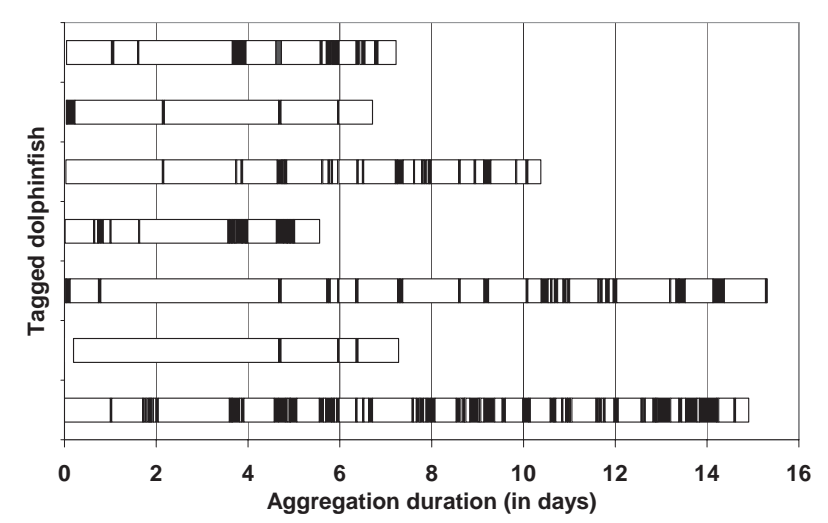

Fig. 5. Excursion pattern of the dolphinfish tagged under the FAD No. 13. White bars correspond to the association periods, dark bars to the excursions (i.e. no detection during more than $30 \mathrm{~min}$ ).

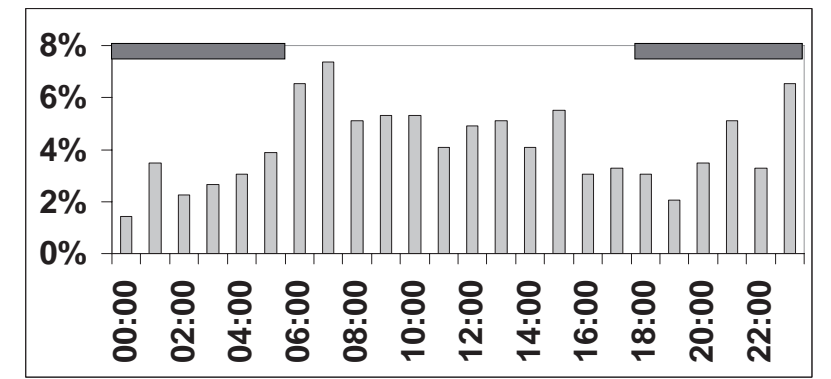

Fig. 6. Periodicity of the dolphinfish excursions within the 24 hours period of the day-night cycle.

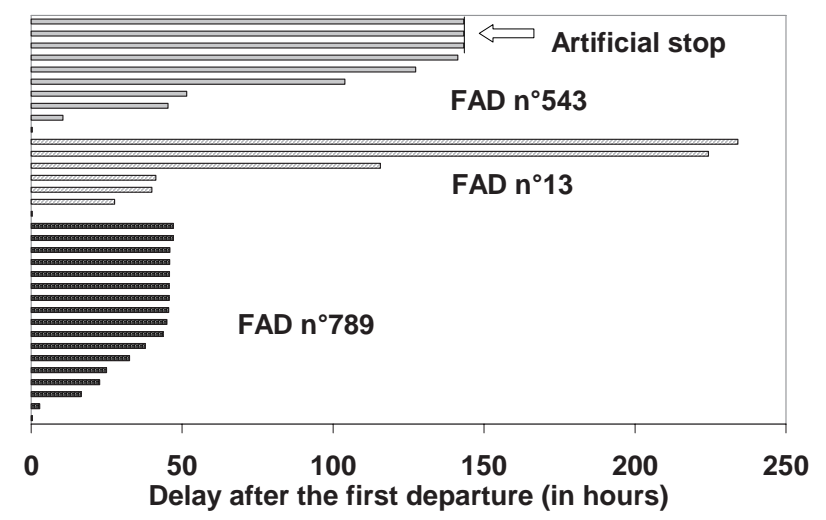

Fig. 7. Detection records showing the timing of departures of dolphinfish from three FADs after a first single departure was recorded.

by underwater visual censuses performed around those FADs (Taquet et al. 2007), where dolphinfish were never observed forming a single large school with synchronous movements, but mainly were observed swimming in small groups of two or more individuals. Some dolphinfish performed synchronous excursions in small groups, while others stayed around the FAD, indicating that the aggregations were composed of several schools. Moreover, the composition of each school did not seem to remain constant.

\section{Discussion}

Ingestion of tags with bait is likely the best technique to avoid associated tagging stress. Unfortunately, the possible regurgitation of tags after short and variable times renders this technique unsuitable for studying fish behavior over long periods of time (Winger and Walsh 2001). This is the most likely cause for the small CRT measured with this technique in our study. Other issues with tag ingestion methods are the possibility of double tagging the same individuals and the impossibility of obtaining very accurate length measurements of the tagged individuals. Surgical implantation of the tags in the intra peritoneal cavity or attaching the tag externally with a hook led to the longest CRT observed in our study. Although those two techniques could be more stressful due to catching and handling, they appear to be the most appropriate techniques to measure residence times.

\subsection{Effects of FADs on dolphinfish behavior}

The mean residence time of dolphinfish around drifting FADs measured in our study was highly variable (6.25 days; $\mathrm{SD}=4.39$ days, maximum 15.26 days). As in all other similar studies (Ohta and Kakuma 2005; Dagorn et al. 2007a), it was not possible to know the original arrival time of each fish to the FADs, so our residence time measurements after tagging should always be considered as under-estimates of the real total FAD residence times.

Since no other study previously estimated the residence times of dolphinfish around FADs, we could not compare our data to other studies on this species, but we can compare them to data derived from tunas. Ohta and Kakuma (2005) and Dagorn et al. (2007a) estimated the average residence time of tunas at anchored FADs to be about 5-8 days. Other studies tagging pelagic fishes around drifting FADs showed yellowfin and bigeye tuna stayed from 3 to 15 days around drifting FADs in the Pacific and Indian oceans. Residence times of dolphinfish and tunas at FADs were similar.

Determining the residence times of fishes around drifting FADs is an important step to estimate the impacts of this aggregated behavior on the spatial dynamic of fish. In particular, this is essential to study if FADs can act as ecological traps (Marsac et al. 2000). This theory stipulates that FADs may be so effective in attracting and retaining fishes that they can alter larger-scale migration patterns and therefore result in a detrimental effect on the biology of these species. First of all, fish must stay for long periods of time around FADs or within a network of FADs (e.g. several weeks) to be affected by the ecological trap effect. The residence times measured in this study were both short and long (up to 2 weeks), which does not allow us to evaluate the ecological trap concept with the present data. Complementary data are needed. FADs could act as ecological traps if fish cannot fulfill their energetic requirements while associated to FADs. Taquet (2004) found that $27 \%$ of dolphinfish diet comes from FAD associated prey, which is certainly not negligible, and could explain how dolphinfish stay several days or weeks associated to FADs. 


\subsection{Activities of dolphinfish at FADs}

We hypothesized that tagged dolphinfish were beyond the detection ranges of our receivers around FADs were involved in an excursion. The fact that dolphinfish could be out of range of the receivers and come back to the FAD, shows that dolphinfish are able to home back to FADs from at least distances of $655 \mathrm{~m}$. This is in agreement with the results from Girard et al. (2007) who showed, using displacement experiments with acoustic tags, that dolphinfish are able to orientate towards a FAD area from at least $820 \mathrm{~m}$.

Our data showed that the duration of excursions away from FADs was quite constant and short (mean $=1 \mathrm{~h} 37, \mathrm{SD}=1 \mathrm{~h}$ 10). When summing all the excursions performed by individual dolphinfish, it appears that fish spend about $8 \%$ of their time away from FADs. Holland et al. (1990) considered that the excursions away from FADs by tunas (which were longer than the ones measured here on dolphinfish) could be due to foraging events. Taquet (2004) showed that $73 \%$ of the dolphinfish diet in the Indian Ocean comes from prey not associated to FADs (such as flying fishes). Therefore, we can assume that the low percentage of time spent by dolphinfish away from FADs (about $8 \%$ ) represents an essential daily activity as this is likely to correspond to major feeding events occurring at day $(60 \%)$ and night $(40 \%)$, without any clear pattern and probably linked to the detection of prey in the vicinity of the FADs.

\subsection{Schooling behavior of dolphinfish}

The synchronous departure of eight dolphinfish from the FAD No. 789 could be interpreted as possible predator avoidance event. Actually, hours before this departure, divers observed the arrival of a big blue marlin (Makaira nigricans) to this FAD. However, our results show that usually all dolphinfish of a same FAD do not leave it by the same time. Most likely dolphinfish form multiple small schools around FADs, as it has been shown for tunas around anchored FADs from acoustic tagging (Dagorn et al. 2007a) and drifting FADs from empirical knowledge of fishermen (Moreno et al. 2007). Underwater visual observations performed in the equatorial FADs (Taquet et al. 2007) confirmed that dolphinfish aggregated around a FAD do not form a single homogeneous school, but are often observed forming several dynamic independent sub-groups. Our data suggests that the composition of schools change over time and that the FADs could be a place of exchanges of individuals between schools. One of the hypotheses to explain why fish associate to FADs is the meeting point theory (Dagorn and Fréon 1999; Fréon and Dagorn 2000), which proposes enhancement of fish aggregations by floating objects by improving the encounter rate between small schools, between isolated individuals or both. Our data indicate that several schools commonly occur around a FAD, which could correspond to the first part of the theory (a place where multiple schools arrive to). Though we do not know if the sizes of the schools leaving the FAD are larger than the ones which arrived, as suggested by the meeting point hypothesis.

\section{Conclusion}

This study indicates that dolphinfish can stay several days associated to FADs (mean 6.25 days, maximum 15.26 days), drifting with them. While associated to FADs, they spend most of their time close to them $(<365 \mathrm{~m})$, but the excursions away from FADs, although they represent a low percentage of their activity (about $8 \%$ ), could be essential as they could correspond to major foraging activities. One key question is to know if dolphinfish could be trapped by FADs or networks of FADs in areas where they could not meet their energetic requirements (ecological trap hypothesis). One needs fine-scale data on abundance of prey in FAD areas to conclude. However, Taquet (2004) found that $27 \%$ of the diet of dolphinfish (in weight) depends on prey associated to FADs. It is therefore possible that even when a FAD crosses an area with low prey abundance, the FAD could serve as a feeding reserve for the dolphinfish, allowing the dolphinfish to stay longer around FADs without a strong impact on their biology. This hypothesis must be studied in future research. Moreover, we have shown that dolphinfish do not form a single school while associated to FADs, and that FADs are likely to be sites with exchanges of individuals between schools. The precise dynamics of these schools must be studied to investigate the role of FADs on the schooling behavior of dolphinfish (meeting point hypothesis).

Acknowledgements. This work was co-funded by the E.U. Fadio Project (DG Research - QLRI-CT- 2002-02773) and the EU DORADE project (DIRED-IFREMER No. 31008/DIRED/JPP/rp) with the additional support of the Regional Council of Reunion Island. Charlotte Girard benefited from a PhD grant from the Regional Council of Reunion Island. We would like to sincerely thank all scientists who helped us in the field works: Patrice Dewals, Christophe Peignon, Bertrand Wendling, from the FADIO team, and Julien Barde, Jérôme Bourjea, Tim Dempster, Didier Leroy, Dominique Miossec, David Roos from the DORADE team. We are grateful to the crews of the M/V "Indian Ocean Explorer" and "Cap Morgan" fishing vessel. Many thanks to the French and Spanish skippers of the purse-seine fishing fleet for their collaboration on their drifting FADs.

\section{References}

Beardsley G.L., 1967, Age, growth and reproduction of the dolphin, Coryphaena hippurus, in the Straits of Florida. Copeia 1967, 2, 441-451.

Brill R.W., Block B.A., Boggs C.H., Bigelow K.A., Freund E.V., Marcinek D.J., 1999, Horizontal movements and depth distribution of large adult yellowfin tuna (Thunnus albacares) near the Hawaiian Islands, recorded using ultrasonic telemetry: implications for the physiological ecology of pelagic fishes. Mar. Biol. 133, 395-408.

Dagorn L., Holland K.N., Itano D.G., 2007, Behaviour of yellowfin (Thunnus albacares) and bigeye (T. obesus) tuna in a network of fish aggregating devices (FADs). Mar. Biol. 151, 595-606.

Dagorn L., Pincock D., Girard C., Holland K., Taquet M., Sancho G., Itano D., Aumeeruddy R. 2007. Satellite-linked acoustic receivers to observe behavior of fishes in remote areas. Aquat. Living Resour. 20, 307-312. 
Dempster T., Kingsford M.J., 2003, Homing of pelagic fish to fish aggregating devices (FADs): an investigation of the role of sensory cues. Mar. Ecol. Prog. Ser. 258, 213-222.

Dempster T., Taquet M., 2004, Analysis of the literature on fish aggregation devices (FAD) research; gaps in current knowledge and future research directions for studies of FAD-associated fish. Rev. Fish. Biol. Fish. 14, 21-42.

Fonteneau A., 2003, Prospects for management of FAD fisheries in the Indian Ocean. IOTC Proc. 6, 30-47.

Fonteneau A., Pallares P., Pianet R., 2000, A worldwide review of purse seine fisheries on FADs. In: Le Gall J.-Y., Cayré P., Taquet M. (eds.), Pêche thonière et dispositifs de concentration de poissons. IFREMER, Actes Colloq. 28, pp. 15-34.

Girard C., Benhamou S., Dagorn L., 2004, FAD: Fish Aggregating Device or Fish Attracting Device? A new analysis of yellowfin tuna movements around floating objects. Anim. Behav. 67, 319326.

Girard C., Dagorn L., Taquet M., Aumeeruddy R., Peignon C., Benhamou S., 2007, Homing abilities of dolphinfish (Coryphaena hippurus) displaced from fish aggregating devices (FADs) determined using ultrasonic telemetry. Aquat. Living Resour. 20, 313-321.

Heupel M.R., Simpfendorfer C.A., Hueter R.E., 2004, Estimation of shark home ranges using passive monitoring techniques. Environ. Biol. Fishes 71, 135-142.

Holland K.N., Brill R.W., Chang R.K.C., 1990, Horizontal and vertical movements of yellowfin and bigeye tunas associated with Fish Aggregating Devices. Fish. Bull. 88, 493-507.

Klimley A.P., Holloway C.F., 1999, School fidelity and homing synchronicity of yellowfin tuna Thunnus albacares. Mar. Biol. 133, 307-317.

Marsac F., Cayre P., 1998, Telemetry applied to behaviour of yellowfin tuna (Thunnus albacares, Bonnaterre, 1788) movements in a network of fish aggregating devices. Hydrobiologia 371/372, 155-171.

Marsac F., Fonteneau A., Menard F., 2000, Drifting FADs used in tuna fisheries: an ecological trap? In: Le Gall J.-Y., Cayre P. and Taquet M. (eds.), Pêche thonière et dispositifs de concentration de poissons. IFREMER, Actes Colloq. 28, pp. 537-552.
Meyer C.G., Holland K.N., 2000, Movement patterns, habitat utilization, home range size and size fidelity in the white-saddle goatfish, Parupeneus porphyreus, in a marine reserve. Environ. Biol. Fish. 59, 235-242.

Ohta I., Kakuma S., 2005, Periodic behaviour and residence time of yellowfin and bigeye tuna associated with fish aggregating devices around Okinawa Islands, as identified with automated listening stations. Mar. Biol. 146, 581-594.

Ohta I, Kakuma S., Kanashiro K., 2001, Aggregating behaviour of yellowfin and bigeye tuna tagged with coded ultrasonic transmitters around FADs in Okinawa, Japan. Proc. Symp. Tagging and Tracking Marine Fish with Electronic Devices, February 7-11, 2000. University of Hawaii, pp. 131-145.

Pincock D.G., Voegeli F.A. 1990, Quick course in underwater telemetry system. Vemco Limited.

Romanov E.V., 2002, By-catch in the tuna purse-seine fisheries of the Western Indian Ocean. Fish. Bull. 100, 90-105.

Schaefer K.M., Fuller D.W., 2002, Movements, behaviour, and habitat selection of bigeye tuna (Thunnus obesus) in the eastern equatorial Pacific, ascertained through archival tags. Fish. Bull. 100, $765-788$.

Topping D.T., Lowe C.G., Caselle J.E., 2006, Site fidelity and seasonal movement patterns of adult California sheephead Semicossyphus pulcher (Labridae): an acoustic monitoring study. Mar. Ecol. Prog. Ser. 326, 257-267.

Taquet M., 2004, Le comportement agrégatif de la dorade coryphène (Coryphaena hippurus) autour des objets flottants. Thèse de Doctorat, Université de Paris 6, Océanologie biologique.

Taquet M., Sancho G., Dagorn L., Gaertner J.C., Itano D., Aumeeruddy R., Wendling B., Peignon C., 2007, Characterization of fish aggregations associated with drifting fish aggregating devices (FADs) in the Western Indian Ocean through underwater visual census. Aquat. Living Resour. 20, 331-341.

Winger P.D., Walsh S.J., 2001, Tagging of Atlantic cod ( Gadus morhua) with intragastric transmitter: effects of forced insertion and voluntary ingestion on retention, food consumption and survival. J. Appl. Ichthyol. 17, 234-239. 